\title{
Primary peritoneal and ovarian cancers: an epidemiological comparative analysis
}

\author{
Delores J. Grant • Patricia G. Moorman • \\ Lucy Akushevich · Rachel T. Palmieri • \\ Rex C. Bentley $\cdot$ Joellen M. Schildkraut
}

Received: 18 November 2009/Accepted: 10 February 2010/Published online: 23 March 2010

(C) The Author(s) 2010. This article is published with open access at Springerlink.com

\begin{abstract}
We performed case-control analyses using data from the North Carolina Ovarian Cancer Study to determine risk factors that distinguish primary peritoneal cancer (PPC) from epithelial ovarian cancer (EOC). Our risk factor analyses were restricted to invasive serous cancers including 495 EOC cases, 62 PPC cases and 1,086 control women. Logistic regression analyses were used to calculate adjusted odds ratios and $95 \%$ confidence intervals for risk factor associations. Although many case-control associations for the invasive serous PPC cases were similar to those of the invasive serous EOC cases, some differences were observed including a twofold increase in risk of invasive serous PPC in women who were $\geq 35$ years at last pregnancy, whereas a decreased risk was observed for invasive serous EOC risk. We could not confirm a previous report of an association between tubal ligation and PPC, a factor consistently associated with a decreased risk of EOC. The difference in the risk factor associations between
\end{abstract}

D. J. Grant

Cancer Research Program, JLC-Biomedical/Biotechnology Research Institute and Department of Biology, North Carolina Central University, Durham, NC, USA

P. G. Moorman · L. Akushevich · J. M. Schildkraut ( $\square)$ Cancer Prevention, Detection and Control Research Program, Duke University Medical Center, Box 2949, Durham,

NC 27710, USA

e-mail: schil001@mc.duke.edu

\section{R. T. Palmieri}

Department of Epidemiology, Gillings School of Global Public Health, University of North Carolina at Chapel Hill,

Chapel Hill, NC, USA

R. C. Bentley

Department of Pathology, Duke University Medical Center, Durham, NC, USA invasive serous PPC and EOC cancers suggests divergent molecular development of peritoneal and ovarian cancers. A larger study to determine risk factors for invasive serous PPC is warranted.

Keywords Primary peritoneal cancer - Ovarian cancer . Epidemiology $\cdot$ Case-control study $\cdot$ Risk factors

\section{Introduction}

Primary peritoneal cancer (PPC) arises in the tissue that lines the abdominal cavity and pelvic cavity [1]. It is an uncommon disease that shares many histopathologic and clinical characteristics with epithelial ovarian cancer (EOC), but PPC is distinguished by the absence of a malignant/invasive ovarian mass [2]. The incidence of PPC is considerably lower than that of EOC (6.78 cases per million vs. 120.5 cases per million, respectively), but PPC incidence has increased at a faster rate than ovarian cancer over the past three decades [3, 4]. However, it is not clear whether this change is due to diagnostic changes or a true increase.

It is uncertain whether PPC is a distinct disease from EOC or if they share common origins. Features shared by both PPC and EOC include the preponderance of serous histology, the advanced stage at diagnosis for the majority of women and similar responsiveness to platinum/taxane chemotherapy [2]. The similarities of these cancers as well as cancers of the fallopian tubes have led to the suggestion that each of these cancer types develops from a common cell lineage, the embryonic Möllerian system [5]. Evidence supporting this argument is the observation that destruction of portions of the Müllerian duct by tubal ligation or hysterectomy reduces the risk of ovarian cancer [5]. 
Epidemiologic data on risk factors for PPC are very limited [6-8]. A recent study from Australia [8] reported many similarities in risk factors for PPC and EOC, but also reported that parous women are at increased risk of PPC. This same study found that obesity was associated with risk of PPC but not EOC. It has been reported that BRCA1 and BRCA2 mutation carriers, including those who have undergone prophylactic bilateral oophorectomy, are at increased risk of PPC [9, 10]. The observed differences in relationships with certain risk factors are suggestive that PPC and EOC may be distinct disease entities, but further data from other studies are needed. In this paper, we present results of an analysis that compared clinical characteristics and risk factors for EOC and PPC of invasive serous histology in a population-based, case-control study in North Carolina.

\section{Materials and methods}

\section{Study population}

The subjects in this study are from the North Carolina Ovarian Cancer Study (NCOCS), a population-based, case-control study of EOC conducted in a 48-county region of North Carolina between 1999 and 2007. Women diagnosed with PPC were also enrolled. Identification and recruitment of EOC and controls has been described in detail in other reports [11-13]. Identical recruitment procedures for EOC cases were applied to PPC cases. Briefly, newly diagnosed cases of primary peritoneal and epithelial ovarian cancer were identified through the North Carolina Central Cancer Registry using a rapid case ascertainment system. Pathology reports for eligible cases were sent to the study office at Duke University Medical Center, and consent to contact the women was requested from the treating physicians. Eligible EOC and PPC cases were aged 20-74 years at diagnosis, had no prior history of ovarian cancer, resided in the study area and were cognitively able to give consent and complete an interview in English. All cases underwent centralized histopathologic review by the study pathologist (RCB) to confirm the diagnosis. Cases were classified by the study pathologist as PPC if they met the Gynecologic Oncology Group criteria [14]: (1) ovaries are normal in size or enlarged by a benign process; (2) the extraovarian sites of carcinoma are of significantly greater volume than the tumor present on either ovary; (3) the ovarian tumor component is nonexistent, confined to the ovarian surface with or without stromal invasion measuring in aggregate less than $5 \times 5 \mathrm{~mm}$, or within the ovarian substance and measuring less than $5 \times 5 \mathrm{~mm}$; and (4) the histologic characteristics indicate serous carcinoma of any grade.
Control women were frequency-matched by age ( 5 year age categories) and race (Black or other) to both invasive and low malignant potential EOC cases who resided in the same 48-county region as the EOC cases using list-assisted random digit dialing. In the present analysis, the age distribution of the cases is somewhat older than that of the controls because we excluded the low malignant potential cases that have a younger age at diagnosis than the invasive cases. Eligibility for controls included at least one intact ovary.

The response rate among the epithelial EOC cases was $66.2 \%$, with nonparticipation due to subject refusal $(11.6 \%)$, death $(4.1 \%)$, debilitating illness $(2.6 \%)$, physician refusal $(4.7 \%)$ and inability to locate $(10.8 \%)$. The response rate for PPC cases was $72.8 \%$, with nonparticipation due to subject refusal $(7.0 \%)$, death $(8.8 \%)$, debilitating disease $(3.5 \%)$, physician refusal $(1.8 \%)$ and inability to locate $(6.1 \%)$. Seventy-three percent of potential controls who passed the eligibility screening agreed to be sent information about the study, and $62 \%$ of those consented to be in the study. Nonparticipation was due to subject refusal $(28 \%)$ and inability to contact $(10 \%)$.

The study protocol was approved by the Duke University Medical Center Institutional Review Board and the human subjects committees at the North Carolina Central Cancer Registry and each hospital where cases were identified.

\section{In-person interview}

For all study subjects, nurse-interviewers conducted in-person visits where they obtained written informed consent, administered a 90-minute standardized questionnaire, drew a blood sample and performed anthropometric measurements (height, weight and waist and hip circumferences). Information obtained with the questionnaire included established and suspected ovarian cancer risk factors including family history of cancer, menstrual characteristics, reproductive history, hormone and contraceptive use, and lifestyle characteristics such as smoking, alcohol consumption and physical activity. A life-events calendar, which marked milestones such as marriages and births, was used to aid recall of reproductive history and hormone use. Pictures of oral contraceptives (OCs), menopausal hormones and certain other medications were also used to assist with recall.

Statistical analysis

Chi-square analyses were used to compare clinical and histologic characteristics between PPC and EOC cases. Unconditional logistic regression analyses were used to calculate age- and race-adjusted and multivariable-adjusted 
odds ratios (ORs) and $95 \%$ confidence intervals (CIs) separately for each disease (PPC or EOC) versus controls. To assess the possibility of residual confounding due to age, we determined whether the addition of the quadratic or cubic terms for age at diagnosis/interview improved the fit of the model. For most variables, the linear term for age produced the best fit. There was no evidence that the cubic age terms improved the fit for any of the analyses in Table 2. Inclusion of both the linear and quadratic terms for age improved the fit of the model for age at last pregnancy, and therefore, the results for this analysis were age-adjusted by including both terms in the model. Casecontrol analyses for both PPC cases and EOC cases were restricted to invasive cancers of the serous histologic subtype since this was the largest category for all cancers. Variables examined included number of pregnancies $(0$, 1-2, 3-4, 5+); ever been pregnant (yes or no); age at last pregnancy (ages 14-24, 25-29, 30-34, 35+); ever breast fed (yes or no), age at menarche (age $0-<12,12+$ ); menopausal status (postmenopausal or premenopausal); tubal ligation (yes or no); hysterectomy at least 1 year prior to diagnosis/interview (yes or no); history of doctor-diagnosed infertility (yes or no); years of OCs or patch use $(<1$, $1-<5,5+$ ); menopausal hormones (yes or no); family history of ovarian cancer in a first degree relative (yes or no); family history of breast cancer in a first degree relative (yes or no); talc use (yes or no); and body mass index (BMI) 1 year before diagnosis (measurements $13-<25,25-$ $<30,30-<35,35+\mathrm{kg} / \mathrm{m}^{2}$ ). To test statistical significance of differences in age-at-last-pregnancy trends between PPC and EOC cases, we used logistic regression controlling for age, race and number of pregnancies and restricting subjects to those who were ever pregnant. To test for possible heterogeneity for risk factor associations in PPC and EOC, we performed case-only comparisons for age at last pregnancy, a family history of breast cancer and hysterectomy using logistic regression, adjusting for both age and race.

\section{Results}

Clinical characteristics of the PPC and EOC cases enrolled in NCOCS are found in Table 1. While a majority of both the PPC and EOC cases were invasive, a larger proportion of low malignant potential tumors were found in the EOC cases $(20.5 \%$ vs. $5.1 \%$ of the PPC cases). We found statistically significant differences in the distributions of histologic subtypes of women with invasive PPC compared to those diagnosed with invasive EOC; a larger portion of the invasive PPC cases were serous compared to the invasive EOC cases. Among the invasive serous cases, women with PPC were less likely to have a well-differentiated grade compared to invasive EOC cases. Invasive serous PPC cases were also more likely to be diagnosed at later stages than the invasive serous EOC cases, $95.2 \%$ versus $85.3 \%$, respectively.

The case-control analyses to determine risk factor associations were restricted to 62 PPC and 495 EOC cases of invasive serous histology and are summarized in Table 2. When compared to EOC cases, the PPC cases

Table 1 Tumor characteristics of primary peritoneal cancer and epithelial ovarian cancer cases

\begin{tabular}{|c|c|c|c|c|c|c|}
\hline & & \multicolumn{2}{|c|}{ Primary peritoneal cancer } & \multicolumn{2}{|c|}{ Ovarian cancer } & $p$-value \\
\hline \multicolumn{2}{|l|}{ All cases } & \multicolumn{2}{|c|}{$(n=78)$} & \multicolumn{2}{|c|}{$(n=1107)$} & \\
\hline \multirow[t]{3}{*}{ Tumor behavior } & Low malignant potential & 4 & $(5.1 \%)$ & 227 & $(20.5 \%)$ & 0.001 \\
\hline & Invasive & 72 & $(92.3 \%)$ & 877 & $(79.2 \%)$ & \\
\hline & Missing & 2 & & 3 & & \\
\hline \multicolumn{2}{|l|}{ Invasive cases } & \multicolumn{2}{|c|}{$(n=72)$} & \multicolumn{2}{|c|}{$(n=877)$} & \\
\hline \multirow[t]{5}{*}{ Histology } & Serous & 62 & $(86.1 \%)$ & 495 & $(56.4 \%)$ & $<0.0001$ \\
\hline & Clear cell & 3 & $(4.2 \%)$ & 87 & $(9.9 \%)$ & \\
\hline & Endometrioid & & & 139 & $(15.8 \%)$ & \\
\hline & Mucinous & & & 48 & $(5.5 \%)$ & \\
\hline & Other & 7 & $7(9.7 \%)$ & 108 & $(12.3 \%)$ & \\
\hline \multicolumn{2}{|l|}{ Invasive serous cases } & \multicolumn{2}{|c|}{$(n=62)$} & \multicolumn{2}{|c|}{$(n=495)$} & \\
\hline \multirow[t]{3}{*}{ Stage } & I or II & 2 & $(3.2 \%)$ & 70 & $(14.1 \%)$ & 0.017 \\
\hline & III or IV & 59 & $(95.2 \%)$ & 422 & $(85.3 \%)$ & \\
\hline & Missing & 1 & & 3 & & \\
\hline \multirow[t]{4}{*}{ Grade } & Well-differentiated & 1 & $(1.6 \%)$ & 45 & $(9.1 \%)$ & 0.027 \\
\hline & Moderately differentiated & 30 & $(48.4 \%)$ & 168 & $(33.9 \%)$ & \\
\hline & Poorly or undifferentiated & 30 & $(48.4 \%)$ & 267 & $(53.9 \%)$ & \\
\hline & Missing & 1 & & 15 & & \\
\hline
\end{tabular}


Table 2 Age- and race-adjusted odds ratios (OR) and 95\% confidence intervals (CI) for case-control analyses of associations between epidemiologic risk factors for invasive serous primary peritoneal cancer versus invasive serous epithelial ovarian cancer

\begin{tabular}{|c|c|c|c|c|}
\hline $\begin{array}{l}\text { Serous primary } \\
\text { peritoneal } \\
\text { cancer }(N=62)\end{array}$ & $\begin{array}{l}\text { Serous epithelial } \\
\text { ovarian cancer } \\
(N=495)\end{array}$ & $\begin{array}{l}\text { Controls } \\
(N=1086)\end{array}$ & $\begin{array}{l}\text { Serous primary } \\
\text { peritoneal cancer } \\
\text { versus controls }\end{array}$ & $\begin{array}{l}\text { Serous epithelial } \\
\text { ovarian cancer } \\
\text { versus controls }\end{array}$ \\
\hline$(\%)$ & $(\%)$ & $(\%)$ & $(95 \% \mathrm{CI})$ & $(95 \% \mathrm{CI})$ \\
\hline
\end{tabular}

\begin{tabular}{|c|c|c|c|c|c|c|c|c|c|c|}
\hline \multicolumn{11}{|c|}{ Age at diagnosis/age at interview (years) } \\
\hline $20-49$ & 4 & $(6.5)$ & 98 & $(19.8)$ & 325 & $(29.9)$ & & & & \\
\hline $50-59$ & 21 & $(33.9)$ & 164 & $(33.1)$ & 339 & $(31.2)$ & & & & \\
\hline $60-69$ & 24 & $(38.7)$ & 162 & $(32.7)$ & 288 & $(26.5)$ & & & & \\
\hline $70+$ & 13 & $(21.0)$ & 71 & $(14.3)$ & 134 & $(12.3)$ & & & & \\
\hline Missing & . & & . & & . & & & & & \\
\hline \multicolumn{11}{|l|}{ Race } \\
\hline Black & 4 & $(6.5)$ & 67 & $(13.5)$ & 189 & $(17.4)$ & & & & \\
\hline White & 56 & $(90.3)$ & 419 & $(84.6)$ & 868 & $(79.9)$ & & & & \\
\hline Other & 2 & (3.2) & 7 & (1.4) & 29 & (2.7) & & & & \\
\hline Missing & . & & 2 & & . & & & & & \\
\hline \multicolumn{11}{|c|}{ Ever been pregnant } \\
\hline No & 9 & $(14.5)$ & 65 & $(13.1)$ & 100 & $(9.2)$ & 1.00 & (Referent) & 1.00 & (Referent) \\
\hline Yes & 53 & $(85.5)$ & 428 & $(86.5)$ & 986 & $(90.8)$ & 0.49 & $(0.23,1.05)$ & 0.59 & $(0.42,0.83)$ \\
\hline Missing & . & & 2 & & . & & & & & \\
\hline \multicolumn{11}{|c|}{ Number of pregnancies } \\
\hline 0 & 9 & $(14.5)$ & 65 & $(13.1)$ & 100 & $(9.2)$ & 1.00 & (Referent) & 1.00 & (Referent) \\
\hline $1-2$ & 19 & $(30.6)$ & 193 & $(39.0)$ & 427 & (39.3) & 0.44 & $(0.19,1.02)$ & 0.63 & $(0.44,0.91)$ \\
\hline $3-4$ & 25 & $(40.3)$ & 183 & $(37.0)$ & 417 & $(38.4)$ & 0.55 & $(0.24,1.23)$ & 0.59 & $(0.41,0.85)$ \\
\hline $5+$ & 9 & $(14.5)$ & 52 & $(10.5)$ & 142 & $(13.1)$ & 0.48 & $(0.18,1.30)$ & 0.45 & $(0.28,0.72)$ \\
\hline Missing & . & & 2 & & . & & & & & \\
\hline$P_{\text {trend }}$ & & & & & & & 0.658 & & 0.022 & \\
\hline \multicolumn{11}{|c|}{ Age at last pregnancy years* } \\
\hline$<25$ & 6 & $(11.3)$ & 117 & $(27.3)$ & 215 & $(21.8)$ & 1.00 & (Referent) & 1.00 & (Referent) \\
\hline $25-29$ & 17 & $(32.1)$ & 155 & $(36.2)$ & 318 & $(32.3)$ & 1.65 & $(0.63,4.29)$ & 0.84 & $(0.62,1.13)$ \\
\hline $30-34$ & 18 & $(34.0)$ & 100 & $(23.4)$ & 290 & $(29.4)$ & 2.20 & $(0.84,5.72)$ & 0.62 & $(0.45,0.86)$ \\
\hline $35+$ & 12 & $(22.6)$ & 52 & $(12.1)$ & 160 & $(16.2)$ & 2.78 & $(1.00,7.78)$ & 0.58 & $(0.39,0.86)$ \\
\hline Missing & . & & 4 & & 3 & & & & & \\
\hline$P_{\text {trend }}$ & & & & & & & 0.126 & & 0.001 & \\
\hline \multicolumn{11}{|l|}{ Ever breastfed } \\
\hline No & 45 & $(72.6)$ & 344 & $(69.5)$ & 695 & $(64.0)$ & 1.00 & (Referent) & 1.00 & (Referent) \\
\hline Yes & 17 & $(27.4)$ & 151 & $(30.5)$ & 391 & $(36.0)$ & 0.71 & $(0.40,1.27)$ & 0.80 & $(0.64,1.01)$ \\
\hline Missing & . & & . & & . & & & & & \\
\hline \multicolumn{11}{|c|}{ History of infertility } \\
\hline No & 53 & $(85.5)$ & 441 & $(89.1)$ & 985 & $(90.7)$ & 1.00 & (Referent) & 1.00 & (Referent) \\
\hline Yes & 9 & $(14.5)$ & 54 & $(10.9)$ & 101 & (9.3) & 1.88 & $(0.89,3.99)$ & 1.26 & $(0.88,1.79)$ \\
\hline Missing & . & & . & & . & & & & & \\
\hline \multicolumn{11}{|c|}{ Age at menarche years } \\
\hline $0-<12$ & 12 & $(19.4)$ & 120 & $(24.2)$ & 216 & (19.9) & 1.00 & (Referent) & 1.00 & (Referent) \\
\hline$>=12$ & 50 & $(80.6)$ & 370 & $(74.7)$ & 867 & $(79.8)$ & 0.90 & $(0.46,1.73)$ & 0.72 & $(0.55,0.93)$ \\
\hline Missing & . & & 5 & & 3 & & & & & \\
\hline \multicolumn{11}{|c|}{ Menopausal status } \\
\hline Postmenopausal & 55 & $(88.7)$ & 365 & $(73.7)$ & 702 & $(64.6)$ & 1.00 & (Referent) & 1.00 & (Referent) \\
\hline Premenopausal & 7 & $(11.3)$ & 122 & $(24.6)$ & 378 & $(34.8)$ & 0.53 & $(0.18,1.54)$ & 0.86 & $(0.60,1.24)$ \\
\hline Missing & . & & 8 & & 6 & & & & & \\
\hline
\end{tabular}


Table 2 continued

\begin{tabular}{|c|c|c|c|c|}
\hline $\begin{array}{l}\text { Serous primary } \\
\text { peritoneal } \\
\text { cancer }(N=62)\end{array}$ & $\begin{array}{l}\text { Serous epithelial } \\
\text { ovarian cancer } \\
(N=495)\end{array}$ & $\begin{array}{l}\text { Controls } \\
(N=1086)\end{array}$ & $\begin{array}{l}\text { Serous primary } \\
\text { peritoneal cancer } \\
\text { versus controls }\end{array}$ & $\begin{array}{l}\text { Serous epithelial } \\
\text { ovarian cancer } \\
\text { versus controls }\end{array}$ \\
\hline$(\%)$ & $(\%)$ & $(\%)$ & $(95 \%$ CI $)$ & $(95 \% \mathrm{CI})$ \\
\hline
\end{tabular}

\section{Tubal ligation}

No

Yes

Missing

Hysterectomy 1 year prior to diagnosis/interview

No
Yes
Missing
OC/patch use years
Never
$0-<1$
$1-<5$
$5+$
Missing
$P_{\text {trend }}$

Menopausal hormones**

No

Yes

Missing

1st Degree family history of ovarian cancer

\begin{tabular}{|c|c|c|c|c|c|c|c|c|c|c|}
\hline No & 56 & $(90.3)$ & 463 & $(93.5)$ & 1053 & $(97.0)$ & 1.00 & (Referent) & 1.00 & (Referent) \\
\hline Yes & 6 & (9.7) & 32 & $(6.5)$ & 30 & $(2.8)$ & 3.48 & $(1.36,8.91)$ & 2.42 & $(1.45,4.05)$ \\
\hline Missing & . & & . & & 3 & & & & & \\
\hline \multicolumn{11}{|c|}{ 1st Degree family history of breast cancer } \\
\hline No & 53 & $(85.5)$ & 394 & $(79.6)$ & 933 & $(85.9)$ & 1.00 & (Referent) & 1.00 & (Referent) \\
\hline Yes & 9 & $(14.5)$ & 101 & $(20.4)$ & 150 & $(13.8)$ & 0.84 & $(0.40,1.75)$ & 1.52 & $(1.14,2.01)$ \\
\hline Missing & . & & . & & 3 & & & & & \\
\hline \multicolumn{11}{|l|}{ Talc use } \\
\hline No & 31 & $(50.0)$ & 204 & $(41.2)$ & 412 & $(37.9)$ & 1.00 & (Referent) & 1.00 & (Referent) \\
\hline Yes & 17 & $(27.4)$ & 158 & $(31.9)$ & 275 & $(25.3)$ & 0.76 & $(0.41,1.42)$ & 1.15 & $(0.89,1.49)$ \\
\hline Missing & 14 & & 133 & & 399 & & & & & \\
\hline \multicolumn{11}{|c|}{ BMI $\left(\mathrm{kg} / \mathrm{m}^{2}\right) 1$ year before diagnosis or interview } \\
\hline $13-<25$ & 29 & $(46.8)$ & 193 & $(39.0)$ & 409 & $(37.7)$ & 1.00 & (Referent) & 1.00 & (Referent) \\
\hline $25-<30$ & 15 & $(24.2)$ & 140 & (28.3) & 321 & (29.6) & 0.63 & $(0.33,1.21)$ & 0.92 & $(0.70,1.19)$ \\
\hline $30-<35$ & 8 & (12.9) & 81 & (16.4) & 172 & $(15.8)$ & 0.69 & $(0.31,1.56)$ & 1.02 & $(0.74,1.40)$ \\
\hline $35+$ & 9 & (14.5) & 64 & (12.9) & 147 & (13.5) & 1.04 & $(0.47,2.30)$ & 1.01 & $(0.71,1.43)$ \\
\hline Missing & 1 & & 17 & & 37 & & & & & \\
\hline$P_{\text {trend }}$ & & & & & & & 0.837 & & 0.624 & \\
\hline
\end{tabular}

Adjustment for age at diagnosis/interview was accomplished in all the analyses using a linear term for age with the exception of age at last pregnancy where both the linear term and quadratic terms were included

* Restricted to those ever pregnant and also controlling for number of pregnancies

** Among postmenopausal

were older and a somewhat lower proportion was Black. There was a significantly increased risk associated with hysterectomy status for both PPC and EOC, $(\mathrm{OR}=1.98$;
95\% $\mathrm{CI}=1.16,3.37$ and $\mathrm{OR}=1.29 ; 95 \% \mathrm{CI}=1.01$, 1.65 , respectively). We also observed a significant increase in the risk of both diseases associated with individuals who 
have a first degree family history of ovarian cancer. The OR was $2.42(95 \% \mathrm{CI}=1.45,4.05)$ for invasive serous EOC; the OR was even higher in magnitude for invasive serous PPC with an OR of 3.48 (95\% CI $=1.36,8.91)$. Among postmenopausal women, menopausal hormone use was found to be significantly associated with EOC with an OR of $1.42(95 \% \mathrm{CI}=1.08,1.86)$. The association between menopausal hormone use and PPC risk was not significant, but the OR was similar in magnitude to that of $\mathrm{EOC}(\mathrm{OR}=1.34 ; 95 \% \mathrm{CI}=0.74,2.42)$. Additionally, the associations between a history of infertility and PPC and EOC suggested an increased risk of both cancers with ORs of $1.88(95 \% \mathrm{CI}=0.89,3.99)$ and $1.26(95 \% \mathrm{CI}=0.88$, 1.79), respectively, although neither was statistically significant.

Several epidemiologic risk factors were found to be similarly inversely related to both invasive serous PPC and invasive serous EOC. The ORs for PPC and EOC in those women who reported that they had ever been pregnant were $0.49 \quad(95 \% \quad \mathrm{CI}=0.23,1.05)$ and $0.59 \quad(95 \%$ $\mathrm{CI}=0.42,0.83)$, respectively, and were similar in magnitude. Additionally, the ORs for having ever breast fed, age at menarche, and menopausal status were also similar in magnitude and direction of the association for both cancer types, although most of the associations were not statistically significant.

Some differences in the association with the risk of the two cancers types were noted. Specifically, among women who were ever pregnant, although of borderline statistical significance, we observed over a twofold increased risk of invasive serous PPC in women who were $\geq 35$ years at last pregnancy $\left(\mathrm{OR}=2.78 ; 95 \% \mathrm{CI}=1.00,7.78, \mathrm{P}_{\text {trend }}=\right.$ $0.126)$. In contrast, a decreasing risk with increasing age at last pregnancy was observed for women diagnosed with invasive serous EOC $(\mathrm{OR}=0.58 ; 95 \% \mathrm{CI}=0.39,0.86$; $\left.\mathrm{P}_{\text {trend }}=0.001\right)$. Using logistic regression comparing invasive serous PPC cases to invasive serous EOC cases, we found a greater than fourfold difference in the association with an age at last pregnancy $\geq 35$ years $(\mathrm{OR}=4.61 ; 95 \%$ $\left.\mathrm{CI}=1.61,13.10 ; \mathrm{P}_{\text {trend }}=0.009\right)$ among those who were ever pregnant (data not shown). Analysis of the association with age at first pregnancy and invasive serous PPC and EOC was also consistent with the associations with age at last pregnancy, where no association with PPC was detected, and increasing age at first birth was associated with a decreased risk of EOC. (data not shown) Although a significant trend for decreasing risk of EOC with increasing number of pregnancies was observed, a similar trend was not observed for PPC risk. For women with invasive serous PPC, no association with having had a tubal ligation $(\mathrm{OR}=1.10 ; 95 \% \mathrm{CI}=0.63,1.93)$ was observed, while having a tubal ligation was inversely related to invasive serous $\mathrm{EOC}$ risk $(\mathrm{OR}=0.72 ; 95 \% \mathrm{CI}=0.57,0.91)$.
However, in a case-only analysis comparing the PPC cases to the EOC cases, the difference in the association with tubal ligation was not statistically significant $(p=0.165)$. Having a family history of breast cancer was not found to be associated with invasive serous PPC in our data $(\mathrm{OR}=0.84 ; 95 \% \mathrm{CI}=0.40,1.75)$, while an increased risk of invasive serous EOC was observed $(\mathrm{OR}=1.52$; $95 \% \mathrm{CI}=1.14,2.01)$. However, a case-only comparison of the association with a family history of breast cancer for invasive serous EOC and PPC did not show evidence of significant heterogeneity in these estimates $(p=0.259)$. Increasing years of use of OCs or the patch was found to be associated with a decreasing trend for the risk of invasive serous EOC. However, a similar trend was not observed for invasive serous PPC most likely due to the small sample size.

Neither cancer type was found to be associated with talc use or a BMI > 35 (see Table 2). However, to address the possibility of confounding between duration of oral contraceptive/patch use, the number of pregnancies and BMI, we simultaneously included all of these factors in an ageand race-adjusted logistic regression model. We did not observe substantial differences in the point estimates, as shown in Table 2, for any of these three factors. (data not shown)

\section{Discussion}

Our results of the case-control analyses suggest that there were differences in some risk factors for invasive serous PPC and EOC cases including a woman's age at last pregnancy, tubal ligation and family history of breast cancer. Among women who were ever pregnant, those whose age at last pregnancy was greater than 35 years had increased risk of invasive serous PPC while this risk factor was found to be protective against invasive serous EOC. Additionally, no association between the risk of invasive serous PPC and a family history of breast cancer and tubal ligation was detected, while women with a family history of breast cancer were at an increased risk of invasive serous EOC and women who had a tubal ligation were at decreased risk of invasive serous EOC.

The number of pregnancies was associated with a decreased risk in both PPC and EOC in the current study. Our results were not consistent with an Australian casecontrol study published by Jordan et al. [8], where serous cancers of the peritoneum were found associated with increased risks among parous women $(\mathrm{OR}=1.8,95 \%$ $\mathrm{CI}=$ 0.-3.9). An analysis by Eltabbakh et al. [6] showed no difference between primary peritoneal and epithelial ovarian cancer cases in women with high numbers of children, although case-control associations were not 
measured. In the current study, we observed the novel finding of a linear relationship between risk of invasive serous PPC and age at last pregnancy, with over a twofold increase in risk at $\geq 35$ years at last pregnancy, while this risk factor was protective in invasive serous EOC cases in the current study. The association between a woman's age at last pregnancy and increased risk of invasive serous PPC in the current study is also inconsistent with the inverse relationship with ovarian cancer in previous studies [15].

Our results showing an increasing risk of invasive serous PPC with older age at last pregnancy suggest differences in cancer development between peritoneal and ovarian carcinomas. The development of peritoneal cancer may not be linked to the protective apoptotic effect resulting in the clearing of mutated cells due to elevated progesterone during pregnancy as hypothesized for ovarian cancer [16]. The contrasting results for risk of PPC and EOC are suggestive of etiological differences in these diseases or tissue origins. If confirmed, this novel finding will need further study to more fully understand the biological basis for why age at last pregnancy would differentially affect the risk of PPC and EOC.

The associations between several other ovarian cancer risk factors and invasive serous PPC are not consistent with that of previous reports. For example, our results of no association of risk with family history of breast cancer were also not consistent with the Australian study that found a family history of breast cancer was associated with an increased risk of PPC [8]. The lack of association with risk of PPC in women with tubal ligation in the current study is also in contrast to the protective effect observed for PPC in a larger, previous case-control study in the Australia [8]. In the current study, we did not observe significant association between age at menarche and invasive serous PPC, although the OR was less than 1.0 for age at menarche $>12$ years of age. These results were not consistent with the study by Eltabbakh et al. [6], which showed that women with serous PPCs had later age at menarche when compared to those with EOC (13.3 years vs. 12.8 years; $p=0.02$ ). However, a small study by Halperin et al. [7] reported that women with serous PPC $(N=28)$ had a significantly earlier age at menarche compared to controls. Small sample sizes likely contributed to these inconsistent findings. Our findings are also inconsistent with that of the Australian study that reported obese women with a BMI $>30$ had double the risk of PPC $(\mathrm{OR}=2.1 ; 95 \% \mathrm{CI}=1.3-3.4)$.

In addition, our results showed that women who had a hysterectomy had an increased risk of both PPC and EOC. The study in Australia by Jordan et al. [8] also showed an increased risk of both cancers. Both studies are inconsistent with conclusions established in previous studies [17]. The results in the Australian study were attributed to a lower age-standardized rate of hysterectomies in the study controls compared to respondents in the 2001 Australian National Health Survey [8]. The prevalence of hysterectomy of $23.1 \%$ in the controls of the NCOCS is similar to that in the general population of North Carolina of $24.6 \%$ as shown in the 2008 North Carolina Behavioral Risk Factor Surveillance Study statistics [18].

Although the prevalence of hysterectomy in our control group is a little lower than in the North Carolina population, this difference would not explain the entire increase in cases that was observed. Therefore, the association with hysterectomy and both EOC and PPC cases in the NCOCS may need further study to determine whether bias or chance explains our unexpected findings.

Consistent with our results, the previous study by Jordan et al. [8] also showed that perineal talc use had no effect on the risk of peritoneal cancer. A second study of PPC, however, reported fewer women with PPC used perineal talc than women with ovarian cancer, 26.0 and $48.1 \%$, respectively ( $p=0.003$ ) [6]. Although chance due to small sample sizes and misclassification bias may play a role in the inconsistent results, this study differed from the current study as well as the Australian study by not restricting the ovarian cancer cases to those of the serous histologic subtype.

Strengths of this study are that it is population-based and only incident cases of PPC and EOC were included. Due to the large size of the NCOCS, we were able to restrict the EOC cases to invasive serous cancers, thus achieving a more homogenous group of ovarian cancers with the same histology of the PPC cases. The small sample size for PPC may have also contributed to our inability to detect significant associations in some instances as well as some chance findings. Nonetheless, the results of the current study provide evidence that suggests etiologic differences between invasive serous PPC and invasive serous EOC, underscoring the need for further research in this area. Uncovering such differences will improve the ability to intervene in the risk of developing invasive serous PPC.

In conclusion, we found similar risk of invasive serous PPC and invasive serous EOC for some but not all ovarian cancer risk factors. Notably, we observed differences when examining risk factors associated with age at last birth, tubal ligation and family history of breast cancer. Studies with larger sample sizes and population diversity are needed to establish risk factors associated with pathophysiology of serous carcinomas.

Acknowledgments Funding for this work was provided by: National Institutes of Health (RO1-CA76016) and the Department of Defense (OC073462). This study would not have been possible without the cooperation of the North Carolina Central Tumor Registry and all of the staff of the North Carolina Ovarian Cancer Study. 
Open Access This article is distributed under the terms of the Creative Commons Attribution Noncommercial License which permits any noncommercial use, distribution, and reproduction in any medium, provided the original author(s) and source are credited.

\section{References}

1. Swerdlow M (1959) Mesothelioma of the pelvic peritoneum resembling papillary cystadenocarcinoma of the ovary; case report. Am J Obstet Gynecol 77(1):197-200

2. Bloss JD, Liao SY, Buller RE, Manetta A, Berman ML, McMeekin S et al (1993) Extraovarian peritoneal serous papillary carcinoma: a case-control retrospective comparison to papillary adenocarcinoma of the ovary. Gynecol Oncol 50(3):347-351

3. Goodman MT, Shvetsov YB (2009) Rapidly increasing incidence of papillary serous carcinoma of the peritoneum in the United States: fact or artifact? Int J Cancer 124(9):2231-2235

4. Goodman MT, Shvetsov YB (2009) Incidence of ovarian, peritoneal, and fallopian tube carcinomas in the United States, 19952004. Cancer Epidemiol Biomarkers Prev 18(1):132-139

5. Dubeau L (2008) The cell of origin of ovarian epithelial tumours. Lancet Oncol 9(12):1191-1197

6. Eltabbakh GH, Piver MS, Natarajan N, Mettlin CJ (1998) Epidemiologic differences between women with extraovarian primary peritoneal carcinoma and women with epithelial ovarian cancer. Obstet Gynecol 91(2):254-259

7. Halperin R, Zehavi S, Langer R, Hadas E, Bukovsky I, Schneider D (2001) Primary peritoneal serous papillary carcinoma: a new epidemiologic trend? A matched-case comparison with ovarian serous papillary cancer. Int J Gynecol Cancer 11(5):403-408

8. Jordan SJ, Green AC, Whiteman DC, Moore SP, Bain CJ, Gertig DM et al (2008) Serous ovarian, fallopian tube and primary peritoneal cancers: a comparative epidemiological analysis. Int J Cancer 122(7):1598-1603
9. Menczer J, Chetrit A, Barda G, Lubin F, Fishler Y, Altaras M et al (2003) Frequency of BRCA mutations in primary peritoneal carcinoma in Israeli Jewish women. Gynecol Oncol 88(1):58-61

10. Casey MJ, Bewtra C (2004) Peritoneal carcinoma in women with genetic susceptibility: implications for Jewish populations. Fam Cancer 3(3-4):265-281

11. Moorman PG, Schildkraut JM, Calingaert B, Halabi S, Vine MF, Berchuck A (2002) Ovulation and ovarian cancer: a comparison of two methods for calculating lifetime ovulatory cycles (United States). Cancer Causes Control 13(9):807-811

12. Schildkraut JM, Calingaert B, Marchbanks PA, Moorman PG, Rodriguez GC (2002) Impact of progestin and estrogen potency in oral contraceptives on ovarian cancer risk. J Natl Cancer Inst 94(1):32-38

13. Schildkraut JM, Murphy SK, Palmieri RT, Iversen E, Moorman PG, Huang Z et al (2007) Trinucleotide repeat polymorphisms in the androgen receptor gene and risk of ovarian cancer. Cancer Epidemiol Biomarkers Prev 16(3):473-480

14. Eichhorn JH, Robboy SR, Bentley RC, Merino M, Russell P (2009) The Peritoneum. In: Robboy SJ, Mutter GL, Prat J, Bentley RC, Russel P, Anderson MC (eds) Robboy's pathology of the female reproductive tract, 2nd edn. Churchill Livingstone/ Elsevier, Edinburgh, pp 909-945

15. Cooper GS, Schildkraut JM, Whittemore AS, Marchbanks PA (1999) Pregnancy recency and risk of ovarian cancer. Cancer Causes Control 10(5):397-402

16. Whiteman DC, Siskind V, Purdie DM, Green AC (2003) Timing of pregnancy and the risk of epithelial ovarian cancer. Cancer Epidemiol Biomarkers Prev 12(1):42-46

17. Permuth-Wey J, Sellers TA (2009) Epidemiology of ovarian cancer. Methods Mol Biol 472:413-437

18. The North Carolina Center for Health Statistics (2008) The North Carolina Behavioral Risk Factor Surveillance Study (NCBRFSS). Available from: www.schs.state.nc.us. 